\title{
Exosomal proteins as potential markers of tumor diagnosis
}

\author{
Aichun Li, Tianbao Zhang, Min Zheng, Yanning Liu* and Zhi Chen*
}

\begin{abstract}
Liquid biopsy especially that of exosomes carries tumor-specific molecules and provides useful information during tumor development and progression in "real time." Exosomes are membrane-encapsulated vesicles, constantly released by multiple cells, including cancer cells, in large quantities, and are widely present in body fluids. Tumor exosomes can remodel a tumor-supportive microenvironment via cross-talk with target cells. Recent research has mainly focused on exosomal miRNAs and to a small degree on proteins. However, detecting the genome output (active proteins such as phosphoproteins) can provide more direct information about disease progression, such as in the early discovery and monitoring of cancers. This review highlights the unique features of exosomal proteins over traditional serological markers and summarizes their recent use in cancer diagnosis and prognosis. Furthermore, we describe the general protocols of research on exosome proteomics with an emphasis on their clinical use.
\end{abstract}

Keywords: Exosomes, Isolation, Detection, Exosomal proteins, Cancer biomarker

\section{Background}

Traditional tissue biopsy might fail to represent tumoral heterogeneity and initiate therapy in time. In contrast, liquid biopsy, including that of circulating tumor cells (CTCs), cell-free DNA (cfDNA), and exosomes, provides comprehensive information about tumors in a noninvasive manner. Additionally, liquid biopsy can be repeatedly used to monitor cancer progress or effective treatment [1]. Liquid biopsy is an invaluable cancer biomarker reservoir.

Exosomal proteins possess unique features over traditional serological markers. First, exosomal proteins have a higher sensitivity compared with proteins directly detected in blood. Nuclear transcription factor, Xbox-binding protein 1 (NFX1), and cGMP-dependent protein kinase 1 (PKG1) are only detected in plasma exosomes [2]. Specific proteins secreted by cancer cells are diluted or combined with other substances like protein-bound PSA in blood which may affect the test results, while there are over $10^{9} / \mathrm{ml}$ exosomes in human blood and individual exosomes typically expose 10-100 surface antigens $[3,4]$. Second, exosomal proteins have a

\footnotetext{
* Correspondence: liuyanning@zju.edu.cn; zjuchenzhi@zju.edu.cn

State Key Laboratory for Diagnosis and Treatment of Infectious Diseases, The First Affiliated Hospital, College of Medicine, Zhejiang University,

Collaborative Innovation Center for Diagnosis and Treatment of Infectious

Diseases, 79\# Qingchun Road, 6A-17, Hangzhou 310003, China
}

higher specificity over secretory proteins. Glypican-1 (GPC1) which was demonstrated specifically enriched on cancer cell-derived exosomes and showed great specificity over CA-199 or serum-free GPC1 (100\% vs $79.49 \%$ vs $82.14 \%$ ) in distinguishing non-cancer subjects from pancreas cancer patients [5]. Third, exosomal proteins are highly stable. Exosomal proteins are protected from external proteases and other enzymes by the lipid bilayer, and phosphorylation proteins can be separated from exosomal samples frozen for 5 years [2]. Tumor is extremely heterogeneous, so the chance to identify a single diagnostic biomarker is likely rare. Exosomes may act as a combination of panel candidate markers including oncogenic protein, mutation DNA, and RNA.

There are currently studies that describe the mechanism of exosomal proteins in regulating tumor progress and summarize their feasibility as tumor markers [6]. However, an understanding of how to realize the clinical application of exosomal proteins in tumor diagnosis and prognosis evaluation is still lacking. This review highlights the specific exosomal proteins in various solid tumors and compares the different exosome isolation methods and means of protein analysis in clinical application. 


\section{Fundamental characteristics and physiological functions of exosomes}

Exosomes are nano-sized $(40-100 \mathrm{~nm})$ vesicles that are produced from multivesicular bodies (MVBs) carrying classic exosomal markers, such as CD9, CD81, and CD63 [7] (Fig. 1). There is agreement that MVBs have two distinct fates in all cells, either fusing with the plasma membrane to release exosomes into the extracellular milieu or fusing with the lysosome where their cargo is digested [8]. High levels of ceramide lipid family proteins appear to help in exosome secretion [9]. Exosomes are naturally released from normal cells and cancer cells found in the blood as well as in urine, ascites, and saliva [10-13]. Exosome cargo is assembled by enzymes, metabolites, proteins, lipids, and nucleic acids, reflecting the cell origin and the organism's physiological conditions and cancer progression [14-19].
Exosomes were once thought to restore the dynamic and homeostatic cellular homeostasis conditions by discarding excess or harmful molecules from cells, such as by eliminating transfer receptors during reticulocyte maturation and removing harmful DNA from the cytoplasm to avoid the senescence or apoptosis of normal human cells [20-22]. In recent years, exosomes have been attributed to multiple biological functions by cell-to-cell communication through direct membrane fusion with the plasma membrane, endosomal membrane, endocytic pathways, or ligand-receptor interactions [23, 24]. Exosomes have been demonstrated to play a vital role in multiple cellular processes, such as inflammation, immune regulation, tissue regeneration, senescence, and cancer [25-28]. However, in this review, we will emphasize the role of exosomes in cancer.

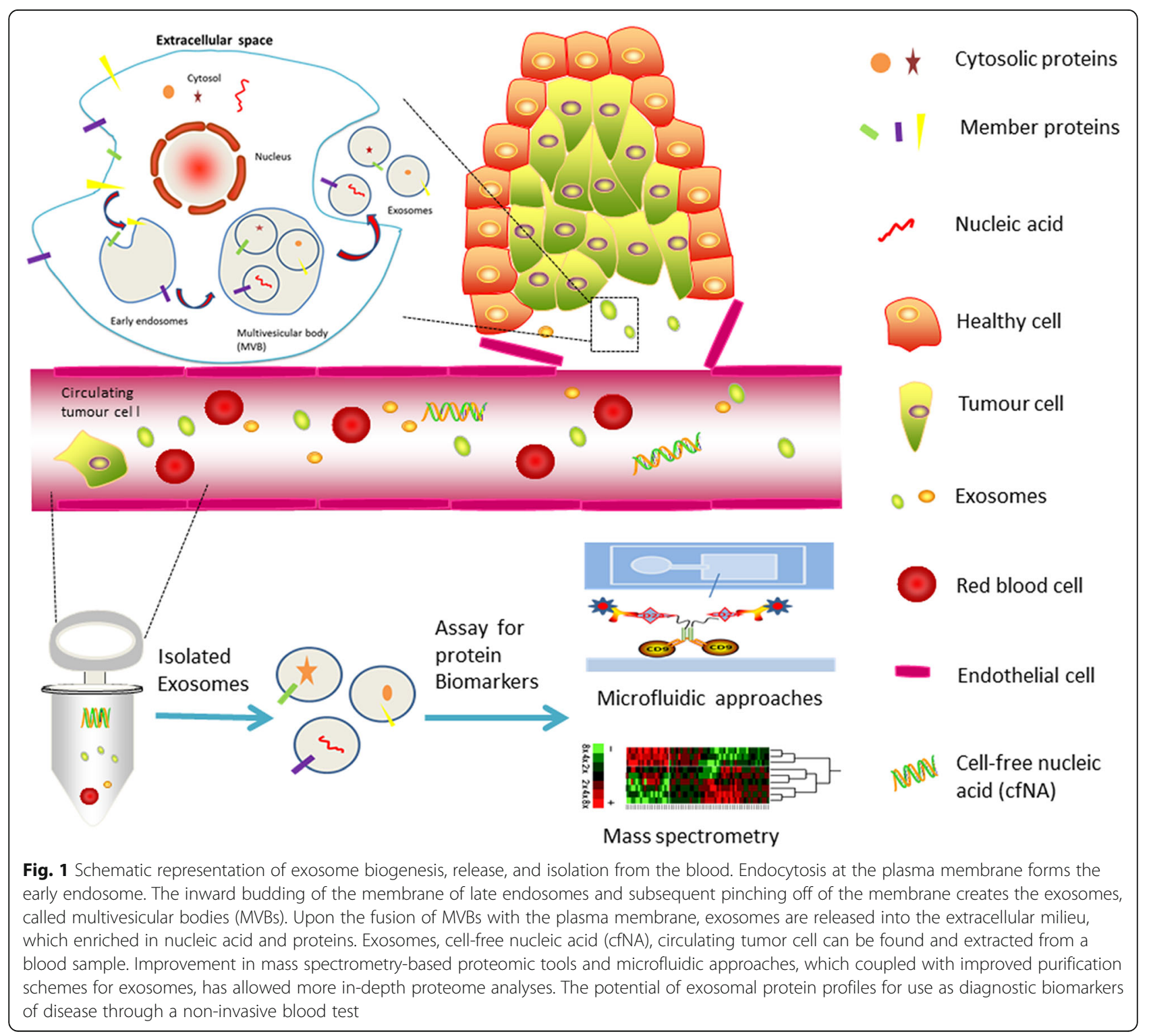




\section{Exosomes' functions in cancer}

Tumor-derived exosomes exchange oncogenic factors with nearby, even distant, cells including cancer-associated fibroblasts, vascular endothelial cells, and immune cells to establish favorable conditions for cancerous growth and metastasis [29]. In physiological states, endogenous RNA is shielded by RNA-binding proteins [30]. However, breast cancer cells can stimulate stromal fibroblasts to produce stromal exosomes, which contain unshielded endogenous RNA (RN7SL1), via triggering NOTCH-MYC pathways. Delivering unshielded RN7SL1 to breast cancer cells facilitates cancer growth, metastasis, and therapy resistance through retinoic acid-inducible gene I (RIG-I) signaling. In addition, more unshielded RN7SL1 was detected in exosomes from patient serum than in normal controls [31]. The level of miR-23a was significantly increased in hypoxic lung cancer-secreted exosomes compared to normoxic parental cells. Exosomal miR-23a promoted angiogenesis by accumulation of hypoxia-inducible factor- $1 \alpha$ (HIF- $1 \alpha$ ) and increased vascular leakiness by inhibiting tight junction protein zonula occludens-1 (ZO-1). Furthermore, the elevated serum levels of lung cancer-derived exosomal miR-23a highlight its potential clinical relevance and prognostic value [32]. Tumor exosomes are not only essential to directing cancer cell migration but also help to form a premetastatic niche before site-specific metastasis [33-36]. Tumor exosomes possess both anti- and pro-tumorigenic potentialities in the body. In chronic lymphocytic leukemia (CLL), non-coding RNAs from tumor exosomes can activate monocytes by activating TLR signaling. The activated monocytes release many cytokines, such as interleukin-6, C-C motif chemokine ligand 4 (CCL4), and CCL2, and express the programmed-death ligand 1 (PDL1), which remodels the tumor-supportive microenvironment [37]. Tumor-derived exosomes carry and deliver tumor antigens to dendritic cells, inducing potent $\mathrm{CD} 8^{+} \mathrm{T}$ cell-dependent antitumor effects in animal experiments [38]. Together, these studies suggest that tumor-derived exosomes play an important role in promoting both primary tumor growth and metastatic spread.

\section{Technology for exosome isolation and identification and analysis of their proteins}

Before launching downstream proteomic studies or functional assays, it is necessary to concentrate and characterize the exosomes in body fluids. In this section, we will summarize commonly used isolation and detection methods as well as general protocols of exosomal protein research.

\section{Methods for isolation exosomes Ultracentrifugation (UC)}

Ultracentrifugation is the gold standard for exosome isolation, accounting for over $56 \%$ users in exosome research [39]. Although ultracentrifugation can produce large amounts of exosomes with great purity, it is unsuitable for clinical diagnosis due to its low throughput which can only detect six samples simultaneously and the repeatability is poor making the study-to-study comparability questionable. Ultracentrifugation is often contained by protein aggregates, and viruses combined with density gradient centrifugation (DGC) can obtain a higher purity of exosomes, but DGC is time-consuming (centrifugation for 16-90 h) which hampers the use in a clinical setting [40]. Currently, based on ultracentrifugation method, glypican 1, PSA has been respectively identified as early diagnostic biomarkers in pancreatic cancer and prostate cancer in blood exosomes [5, 41].

\section{Size exclusion chromatography (SEC)}

Size exclusion chromatography is a gravity flow-based technique to separate exosomes from other vesicles with different sizes [42]. This method has the advantage of maintaining the structural integrity and biological activity of exosomes [43]. In addition, SEC is fast, 10 to 20 min per sample, and relatively inexpensive which makes SEC clinically applicable.

\section{Polymer precipitation}

Isolation exosomes based on polymer precipitation is simple and easy to use and require no specialized equipment and is comparable with both low- and high-sample volumes [44]. However, additional steps are required to remove lipoproteins and polymer using a Sephadex G-25 column to improve exosome separation purity [45]. Serum exosomal carcinoembryonic antigen (CEA) exhibited a better sensitivity and specificity than serum CEA using ExoQuick ${ }^{\text {ru }}$ [46].

\section{Immunocapture assays}

Immunocapture assays can isolate specific subpopulations of exosomes using beads, plate-coated monoclonal antibodies target specific ligand expressed on exosomal surface such as proteins or phosphatidylserine (PS) [47, 48].

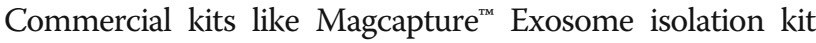
PS and CD63 Dynabeads beads are based on this principle [49]. Immunocapture assays have the advantages of being high throughput, rapid (4-12 h), easy to use, and compatible with routine bench equipment and therefore are clinically applicable. Recently, the level of exosomal PS in circulation was confirmed as a hopeful marker for early diagnosis of malignancies by using sensitive ELISA [50].

\section{Microfluidic technologies}

Although the application of microfluidic technology in exosome isolation is still in its infancy, the small sample size $(5-100 \mu \mathrm{l})$, high purity, high sensitivity, and short operation time $(1.5 \mathrm{~h})$ have made microfluidic 
technology hold good clinical application prospect [51]. But repeatability and consistency remain one of the major challenges. Exosomes are isolated by two types of antibodies and are detected by photosensitizer beads, CD9, and CD147 double-positive exosomes that are enriched in serum from colorectal cancer patients [52].

\section{Strategies for exosome identification and exosomal protein analysis}

It is critically important to assess the recovery and purity of isolated exosomes for proteomic experiments or functional investigations. A particle to protein ratio of $3 \times$ $10^{10}$ or greater has been considered to be high purity [53]. Electron microscopy (EM) can be performed as the gold standard method to check the presence of exosomes with a cup-shaped morphology and even to check the exosomal immunophenotype by immuno-electron microscopy [3]. Nanoparticle tracking analysis (NTA) can be used to determine the concentration and size of exosomes [54]. Exosome concentrations probably range between $10^{7}$ and $10^{9} / \mathrm{mL}$ plasma in physiological conditions [3]. ELISA and Western blots are used to discover established exosomal markers, such as CD9, CD81, and CD63. The "exclusion markers," such as calnexin or the endoplasmic reticulum heat shock protein (GP96), which are unexpected in exosomes, can be detected by Western blot [55].

Highly abundant proteins in the samples were removed using the commercial depletion kit before exosome enrichment, and isolated exosomes were further verified by morphology tests and surface biomarker analysis [56]. Indeed, these proteins are routinely removed before downstream proteomic analysis. In recent literature, the use of mass spectrometry or Extracellular Vesicle (EV) Arrays for proteome analysis is becoming extremely popular for discovering disease-specific proteins [57]. The EV Array is a sandwich ELISA-based method that explores multiple membrane-associated proteins simultaneously [58].

First, we should make sure that the disease-specific proteins are novel by comparing them with the available data in EVpedia, Exocarta, and Vesiclepedia [59-61]. Second, we need to verify these disease-specific proteins in a larger cohort. ELISA and Western blot are widely utilized methods to characterize the presence of a particular protein in exosomes. ELISA captures exosomes by targeting conservative exosomal proteins and quantitatively assesses the tumor-associated proteins. Western blot can identify both the cytosolic proteins and membrane proteins. The immuno-gold-labeling protocol, involving incubating exosomes with antibody-coated gold particles $(4-40 \mathrm{~nm})$, is applied to reveal the presence of tumor-specific membrane proteins under EM [62]. Because of the number of surface antigens in the exosomes $(<100)$ and the size $(<300-500 \mathrm{~nm})$, which is below the detection limit of the conventional flow cytometers, exosomes need to bind to beads and fluorescence-labeled antibodies to evaluate their surface phenotype by most flow cytometers [4]. Recently, researchers developed high-resolution flow cytometry, which allows quantitative and multiparameter qualitative analysis of nano-sized vesicles $(100-200 \mathrm{~nm})$ [63, 64]. The microfluidic device can simultaneously isolate and identify exosome surface proteins without purity processing, which may provide a rapid and high-throughput platform in translational medicine [65]. However, not every research group has this device. In fact, exosome concentration is routinely detected by NTA. Finally, we need to set a cutoff value of exosomal proteins to test and verify their potential clinical relevance in another cohort. Additionally, functional assays are needed to better understand the biological mechanisms of the exosomal surface proteins in general.

\section{The application of exosomal proteins in tumor diagnosis}

Exosomes have gained great attention due to their function in shuttling specific tumor markers in solid tumors. The concentration of exosomal proteins is higher in cancer patients compared with tumor-free individuals. In addition, tumor exosomes contain plenty of cancer biological information [35]. With the development of both proteomic technologies and analytical means for exosomal proteins, the number of papers about exosomal proteins is rapidly increasing. In this section, we highlight the clinical study of exosomal proteins in the early detection and diagnosis of cancer (Table 1).

\section{Thoracic tumors (lung cancer, breast cancer)}

Kristine et al. [57] developed an EV Array that coupled 37 antibodies targeting lung cancer-associated proteins and a panel of CD9, CD63, and CD81 antibodies to explore circulating exosomes from healthy subjects and lung cancer patients. The authors used a combined 30-marker model EV Array, which can successfully distinguish the two groups with $75.3 \%$ accuracy. Using a similar method, it was found that the exosomal protein of New York esophageal squamous cell carcinoma-1 (NY-ESO-1) maintained a significant concentrationdependent impact on inferior survival after multiple testing using the Bonferroni correction method [66]. This approach involved identifying and comprehensively comparing the proteome profiles of saliva and serum exosomes from lung cancer patients and healthy controls by liquid chromatography-tandem mass spectrometry (LC-MS/MS) [11]. Coincidently, a panel of 11 cancer-related proteins was detected in exosomes from the body fluids of lung cancer patients. These proteins may provide a diagnostic source for the early detection 
Table 1 Exosomal proteins as potential diagnostic markers in various tumors

\begin{tabular}{|c|c|c|c|c|c|c|}
\hline Exosomal proteins & Tumor & Body fluid & Isolation method & Detection method & Year & Ref \\
\hline NY-ESO-1 & Lung & Plasma & Extracellular Vesicle Array & Extracellular Vesicle Array & 2016 & {$[66]$} \\
\hline $\begin{array}{l}\text { PKG1, RALGAPA2, } \\
\text { NFX1, TJP2 }\end{array}$ & Breast & Plasma & Ultracentrifugation & Parallel reaction monitoring (PRM) & 2017 & [2] \\
\hline Her2 & Breast & Plasma & Microfluidic chip & Microfluidic chip & 2017 & {$[70]$} \\
\hline Glypican-1 & Breast & Serum & Ultracentrifugation and FACS & FACS & 2016 & [5] \\
\hline Glypican-1 & Pancreatic & Serum & Ultracentrifugation and FACS & Flow-cytometry and ELISA & 2016 & [5] \\
\hline Glypican-1 & Colorectal & Plasma & Immunocapture assays & Flow-cytometry & 2017 & {$[76]$} \\
\hline CEA & Colorectal & Serum & Polymer precipitation & ELISA & 2017 & {$[46]$} \\
\hline $\begin{array}{l}\text { AMPN } \\
\text { VNN1, PIGR }\end{array}$ & Cholangiocarcinoma & Serum & Ultracentrifugation & Western blot & 2016 & {$[77]$} \\
\hline PSA & Prostate & Plasma & Filtration and ultracentrifugation & ELISA and nanoscale flow-cytometry & 2017 & {$[41]$} \\
\hline GGT1 & Prostate & Serum & Ultracentrifugation/DGC/SEC & Western blot and fluorescent probe & 2017 & {$[80]$} \\
\hline $\begin{array}{l}\text { CD24, EpCAM, } \\
\text { CA-125 }\end{array}$ & Ovarian & Plasma & Microfluidic ExoSearch Chip & Microfluidic ExoSearch Chip & 2016 & {$[86]$} \\
\hline
\end{tabular}

and diagnosis of lung cancer once they are validated. It was found that other tumor-specific proteins included plasma exosomal surface EGFR or leucine-rich alpha-2glycoprotein (LRG1) in urinary exosomes, which were identified in lung cancer patients $[67,68]$.

The events of protein phosphorylation may provide clues about disease status [69]. However, few phosphoproteins in biofluids have been reported as disease markers due to their highly dynamic nature and the presence of active phosphatases in blood. Using LC-MS/ MS, researchers identified more than 100 phosphoproteins in plasma exosomes that are significantly higher in breast cancer patients compared with healthy controls. In addition, they applied parallel reaction monitoring (PRM), a quantitative mass spectrometry (MS) approach, to verify four phosphoproteins: cGMP-dependent protein kinase 1 (PKG1), Ral GTPase-activating protein subunit alpha-2 (RALGAPA2), nuclear transcription factor, X-box-binding protein 1 (NFX1), and tight junction protein 2 (TJP2), which showed significant upregulation in breast cancer patients [2]. This study demonstrates that phosphoproteins in plasma exosomes can provide useful real-time information in the early detection and monitoring of cancers. It was shown that the level of plasma epithelial cell adhesion molecule (EpCAM)-positive exosomes was significantly higher in breast cancer patients compared with healthy individuals. Moreover, the level of human epidermal growth factor receptor-2 (HER2) in the plasma exosome was almost consistent with that in the tumor biopsies [70]. The exosomal HER2 in circulation could reflect molecular classification of the tumor tissues in a non-invasive way. The levels of exosomal fibronectin and developmental endothelial locus-1 (EDIL3) were significantly higher in breast cancer patients than controls and dramatically reduced after tumor resection, suggesting that they may serve as important diagnostic and prognostic markers for breast cancer patients [71, 72]. CD24 on circulating exosomes has emerged as a diagnostic biomarker of breast cancer patients [73]. Survivin levels were significantly higher in serum samples from all stages of breast cancer compared to the controls, and survivin was found in tumor tissues, suggesting that it was a part of the exosomes from tumor cells [74]. However, survivin-2B, which is a survivin alternative splice variant, is a pro-apoptotic protein that was inversely related to tumor grade in tumor tissues, which could be a good prognostic marker in this disease.

\section{Gastrointestinal tumors (pancreas cancer, colorectal cancer, cholangiocarcinoma)}

Recent work has demonstrated that special proteins are only present on the exosomes derived from malignant cells [5]. Glypican-1 (GPC1), the cell surface proteoglycan, is overexpressed in breast and pancreatic cancers and is exclusively detected on exosomes derived from those malignant cells. Additionally, the level of GPC1+ exosomes in circulation correlates well with the patient's clinical outcome after removal of pancreatic lesions. However, Lai and colleagues [75] reported that exosomal GPC1 is not able to distinguish pancreatic cancers from non-tumorous controls and that the levels of exosomal GPC1 were only slightly lower after resection. However, the levels of exosomal microRNAs were significantly elevated in pancreatic cancers and normalized following pancreas resection. Nevertheless, large variation among the clinical samples and poor consensus regarding the isolation and detection methods may hinder the integration of the data from different labs. During the early stage of pancreatic cancer progression to liver metastasis, 
the migration inhibitory factor (MIF) was markedly elevated [36]. Application of GPC1 as a diagnostic marker for colorectal cancer (CRC) is also reported. The study showed that both the percentage of GPC1+ exosomes and the GPC1 protein expression in exosomes from tumor tissues and plasma of CRC patients were significantly decreased after surgery compared to those in the peritumoral tissues and plasma of healthy individuals [76]. $\mathrm{CD}^{+} \mathrm{CD} 147^{+}$exosomes were abundant in CRC patient serum using "ExoScreen," and the CD147 level dropped after surgery [52]. Serum exosomal CEA can predict metastatic CRC with a higher sensitivity and accuracy than serum CEA [46]. The high abundance of oncogenic proteins is present in both cholangiocarcinoma (CCA) human cell lines and CCA patient serum, which provided a basis for cholangiocarcinoma diagnosis. In addition, EGFR, Mucin-1 (MUC1), and integrin beta-4 (ITGB4), which promote tumor growth and metastasis, may be bad prognostic factors in this tumor [77]. In fact, exosome concentration is also a useful biomarker in bile to discriminate malignant common bile duct (CBD) stenoses from controls or non-malignant CBD stenoses with $100 \%$ accuracy [78].

\section{Urinary tumors (prostate cancer, bladder cancer)}

Plasmatic PSA is widely used for prostate cancer (PCa) detection and monitoring. However, PSA testing fails to differentiate benign prostatic hypertrophy (BPH) from tumors [79]. It was found that the tumor microenvironmental acidity increased the release of exosomes and influenced PSA by prostate cancer cells. PSA ${ }^{+}$exosomes in the plasma of PCa patients is fourfold greater than that of tumor-free controls [41]. Additionally, it was shown that gammaglutamyltransferase 1 (GGT1), a cellsurface enzyme, was present together with CD9 in exosomes from human serum. Serum exosomal GGT activity and GGT1 expression were significantly higher in PCa patients than in BPH, which may serve as a novel diagnostic marker to distinguish these diseases [80]. Through comparing the proteome of the urinary exosomes of PCa patients with healthy subjects, TM256 and ADIRF have shown the highest diagnostic value [81]. Twenty-nine urinary exosomal proteins have emerged as novel candidate biomarkers, especially tumor-associated calcium-signal transducer 2 (TACSTD2), which was directly quantified by ELISA in urine specimens and confirmed to have potential value for diagnosis of bladder cancer [82]. Bladder cancer exosomes contain EDIL3/Del1 and facilitate cancer progression [83].

\section{Other tumors}

Exosomal proteins have been suggested as novel diagnostic and prognostic indicators for a variety of cancers. Many melanoma-specific exosome proteins, such as caveolin-1, were identified in clinical samples [84]. EGFR, EGFRvIII, and CD63 were detected in serum exosomes of glioblastoma patients [85]. Multiple exosomal proteins, e.g., CD24 and claudin-4, can serve as promising biomarkers of ovarian cancer [86, 87]. In the future, these proteins will need to be further validated in heterogeneous and larger patient cohorts.

\section{Conclusions}

The growing body of functional studies has provided strong evidence that these exo-based markers can be identified for early stage cancer detection, as well as to even predict clinical outcome. Currently, exosomes are isolated primarily by ultracentrifugation or immunocapture. The former is not highly specific and is unsuitable for clinical applications, while the latter may introduce bias and contaminations from serum/plasma proteins. Most of the clinical research on exosomal proteins is still based on the case data from a single group/hospital.

Reproducible isolation and highly sensitive identification methods are needed for research and development. Moreover, we need to standardize the methodology and technology for exosome isolation and identification in order to effectively integrate the data from different labs and enhance their feasibility in clinical application. In addition, their application still should depend on multicenter joint verification to further determine the cutoff value, sensitivity, specificity, and so on. With the improvements in technology, through a simple blood test, exosomal protein content or molecular/genetic profiles can provide preliminary diagnostic and prognostic information for cancer patients. Tissue biopsy and exosomes can be combined in the provision of personalized diagnosis and treatment.

\section{Abbreviations}

ADIRF: Adipogenesis regulatory factor; BPH: Benign prostatic hypertrophy; CBD: Common bile duct; CCA: Cholangiocarcinoma; CCL2: C-C motif chemokine ligand 2; CEA: Carcinoembryonic antigen; CfDNA: Circulating free DNA; CRC: Colorectal cancer; CTCs: Circulating tumor cells; DGC: Density gradient centrifugation; EDIL3: Developmental endothelial locus-1; EDIL-3/ Del1: EGF-like repeats/discoidin I-like domain-3; EGFR: Epidermal growth factor receptor; ELISA: Enzyme-linked immunosorbent assay; EM: Electron microscopy; EpCAM: Epithelial cell adhesion molecules; EV Array: Extracellular Vesicle Array; GGT1: Gammaglutamyltransferase 1; GPC1: Glypican-1; HER2: Human epidermal growth factor receptor-2; HIF-1a: Hypoxia-inducible factor-1a; ITG 34 : Integrin beta-4; LC-MS/MS: Liquid chromatography-tandem mass spectrometry; LRG1: Leucine-rich alpha-2-glycoprotein; MIF: Migration inhibitory factor; MUC1: Mucin-1; MVBs: Multivesicular bodies; NFX1: Nuclear transcription factor, X box-binding protein 1; NTA: Nanoparticle tracking analysis; NY-ESO-1: New York esophageal squamous cell carcinoma-1; PCa: Prostate cancer; PD-

L1: Programmed death ligand 1; PKG1: CGMP-dependent protein kinase 1; PS: Phosphatidylserine; PSA: Prostate-specific antigen; RALGAPA2: Ral GTPaseactivating protein subunit alpha-2; RIG-I: Retinoic acid-inducible gene I; SEC: Size exclusion chromatography; TACSTD2: Tumor-associated calcium-signal transducer 2; TJP2: Tight junction protein 2; TLR: Toll-like receptor;

TM256: Transmembrane protein 256; ZO-1: Zonula occludens-1

Acknowledgements

Not applicable 


\section{Funding}

This work was supported by the major social development projects of Zhejiang S\&T Major Projects (nos. $2015 C 03045$ and 2018C03019).

\section{Availability of data and materials}

Data sharing is not applicable to this article as no datasets were generated or analyzed during the current study.

\section{Authors' contributions}

LA performed the selection of literature, drafted the manuscript, and prepared the figures. ZT and ZM collected the related references and participated in the discussion. LY and CZ carried out the design and language revision of the manuscript. All authors read and approved the final manuscript.

\section{Ethics approval and consent to participate}

Not applicable

\section{Consent for publication}

Not applicable

\section{Competing interests}

The authors declare that they have no competing interests.

\section{Publisher's Note}

Springer Nature remains neutral with regard to jurisdictional claims in published maps and institutional affiliations.

Received: 3 November 2017 Accepted: 8 December 2017

Published online: 27 December 2017

\section{References}

1. Zhang $W$, Xia W, LV Z, Ni C, Xin Y, Yang L. Liquid biopsy for cancer: circulating tumor cells, circulating free DNA or exosomes? Cell Physio Biochem. 2017:41(2):755-68.

2. Chen IH, Xue L, Hsu CC, Paez JS, Pan L, Andaluz H, Wendt MK, lliuk AB, Zhu JK, Tao WA. Phosphoproteins in extracellular vesicles as candidate markers for breast cancer. Proc Natl Acad Sci U S A. 2017;114(12):3175-80.

3. Arraud N, Linares R, Tan S, Gounou C, Pasquet JM, Mornet S, Brisson AR. Extracellular vesicles from blood plasma: determination of their morphology, size, phenotype and concentration. J Thromb Haemost. 2014 12(5):614-27.

4. Nolan JP. Flow cytometry of extracellular vesicles: potential, pitfalls, and prospects. Curr Protoc Cytom. 2015;73:13.14.11-6.

5. Melo SA, Luecke LB, Kahlert C, Fernandez AF, Gammon ST, Kaye J, LeBleu VS, Mittendorf EA, Weitz J, Rahbari N, et al. Glypican-1 identifies cancer exosomes and detects early pancreatic cancer. Nature. 2015:523(7559):177-82.

6. Li W, Li C, Zhou T, Liu X, Liu X, Li X, Chen D. Role of exosomal proteins in cancer diagnosis. Mol Cancer. 2017;16(1):145

7. Thery C, Zitvogel L, Amigorena S. Exosomes: composition, biogenesis and function. Nat Rev Immunol. 2002;2(8):569-79.

8. Harding C, Heuser J, Stahl P. Endocytosis and intracellular processing of transferrin and colloidal gold-transferrin in rat reticulocytes: demonstration of a pathway for receptor shedding. Eur J Cell Biol. 1984;35(2):256-63.

9. Mobius W, Ohno-Iwashita Y, van Donselaar EG, Oorschot VM, Shimada Y, Fujimoto T, Heijnen HF, Geuze HJ, Slot JW. Immunoelectron microscopic localization of cholesterol using biotinylated and non-cytolytic perfringolysin O. J Histochem Cytochem. 2002;50(1):43-55.

10. Caby MP, Lankar D, Vincendeau-Scherrer C, Raposo G, Bonnerot C. Exosomal-like vesicles are present in human blood plasma. Int Immunol. 2005;17(7):879-87.

11. Sun Y, Liu S, Qiao Z, Shang Z, Xia Z, Niu X, Qian L, Zhang Y, Fan L, Cao CX, et al. Systematic comparison of exosomal proteomes from human saliva and serum for the detection of lung cancer. Anal Chim Acta. 2017:982:84-95.

12. Pisitkun T, Shen RF, Knepper MA. Identification and proteomic profiling of exosomes in human urine. Proc Natl Acad Sci U S A. 2004;101(36):13368-73.

13. Andre F, Schartz NE, Movassagh M, Flament C, Pautier P, Morice P, Pomel C, Lhomme C, Escudier B, Le Chevalier T, et al. Malignant effusions and immunogenic tumour-derived exosomes. Lancet (London, England). 2002; 360(9329):295-305
14. Iraci N, Gaude E, Leonardi T, Costa ASH, Cossetti C, Peruzzotti-Jametti L. Extracellular vesicles are independent metabolic units with asparaginase activity. Nat Chem Biol. 2017;13(9):951-5.

15. Li Y, Zheng Q, Bao C, Li S, Guo W, Zhao J, Chen D, Gu J, He X, Huang S. Circular RNA is enriched and stable in exosomes: a promising biomarker for cancer diagnosis. Cell Res. 2015;25(8):981-4.

16. Puhka 1M, Takatalo 2M, Nordberg 1M-E, Valkonen S: Metabolomic profiling of extracellular vesicles and alternative normalization methods reveal enriched metabolites and strategies to study prostate cancer-related changes. Theranostics. 2017;7(16):3824-41.

17. De Gassart A, Geminard C, Fevrier B, Raposo G, Vidal M. Lipid raft-associated protein sorting in exosomes. Blood. 2003;102(13):4336-44.

18. Thakur BK, Zhang H, Becker A, Matei I, Huang Y, Costa-Silva B, Zheng Y, Hoshino A, Brazier H, Xiang J, et al. Double-stranded DNA in exosomes: a novel biomarker in cancer detection. Cell Res. 2014:24(6):766-9.

19. Valadi H, Ekstrom K, Bossios A, Sjostrand M, Lee JJ, Lotvall JO. Exosomemediated transfer of mRNAs and microRNAs is a novel mechanism of genetic exchange between cells. Nat Cell Biol. 2007;9(6):654-9.

20. Rashed HM, Bayraktar E, Helal KG, Abd-Ellah M, Amero P, Chavez-Reyes A, Rodriguez-Aguayo C. Exosomes: from garbage bins to promising therapeutic targets. Int J Mol Sci. 2017;18(3):538.

21. Takahashi A, Okada R, Nagao K, Kawamata Y, Hanyu A, Yoshimoto S, Takasugi M, Watanabe S. Exosomes maintain cellular homeostasis by excreting harmful DNA from cells. Nat Commun. 2017;8:15287.

22. Pan BT, Johnstone RM. Fate of the transferrin receptor during maturation of sheep reticulocytes in vitro: selective externalization of the receptor. Cell. 1983;33(3):967-78

23. Montecalvo A, Larregina AT, Shufesky WJ, Stolz DB, Sullivan ML, Karlsson JM, Baty CJ, Gibson GA, Erdos G, Wang Z, et al. Mechanism of transfer of functional microRNAs between mouse dendritic cells via exosomes. Blood. 2012;119(3):756-66.

24. Verdera HC, Gitz-Francois JJ, Schiffelers RM, Vader P. Cellular uptake of extracellular vesicles is mediated by clathrin-independent endocytosis and macropinocytosis. J Control Release. 2017;

25. Shefler I, Salamon P, Levi-Schaffer F, Mor A, Hershko AY, Mekori YA. MicroRNA-4443 regulates mast cell activation by $T$ cell-derived microvesicles. J Allergy Clin Immunol. 2017. [Epub ahead of print]

26. Kumar B, Garcia M, Weng L, Jung X, Murakami JL, Hu X: Acute myeloid leukemia transforms the bone marrow niche into a leukemia-permissive microenvironment through exosome secretion. 2017.

27. Tassew NG, Charish J, Shabanzadeh AP, Luga V, Harada H, Farhani N, D'Onofrio P, Choi B, Ellabban A, Nickerson PEB, et al. Exosomes mediate mobilization of autocrine Wnt10b to promote axonal regeneration in the injured CNS. Cell Rep. 2017;20(1):99-111.

28. Zhang Y, Kim MS, Jia B, Yan J, Zuniga-Hertz JP, Han C, Cai D. Hypothalamic stem cells control ageing speed partly through exosomal miRNAs. Nature. 2017:548(7665):52-7.

29. Figueroa J, Phillips LM, Shahar T, Hossain A, Gumin J, Kim H, Bean AJ, Calin GA, Fueyo J, Walters ET, et al. Exosomes from glioma-associated mesenchymal stem cells increase the tumorigenicity of glioma stem-like cells via transfer of miR-1587. Cancer Res. 2017;

30. Devarkar SC, Wang C, Miller MT, Ramanathan A, Jiang F, Khan AG, Patel SS, Marcotrigiano J. Structural basis for m7G recognition and 2'-O-methyl discrimination in capped RNAs by the innate immune receptor RIG-I. Proc Natl Acad Sci U S A. 2016:113(3):596-601.

31. Nabet BY, Qiu Y, Shabason JE, Wu TJ, Yoon T, Kim BC, Benci JL, DeMichele AM, Tchou J, Marcotrigiano J, et al. Exosome RNA unshielding couples stromal activation to pattern recognition receptor signaling in cancer. Cell. 2017;170(2):352-66. e313

32. Hsu YL, Hung JY, Chang WA, Lin YS, Pan YC, Tsai PH, Wu CY, Kuo PL. Hypoxic lung cancer-secreted exosomal miR-23a increased angiogenesis and vascular permeability by targeting prolyl hydroxylase and tight junction protein ZO-1. Oncogene. 2017;36(34):4929-42.

33. Hoshino A, Costa-Silva B, Shen TL, Rodriques G, Hashimoto A, Tesic Mark M, Molina H, Kohsaka S, Di Giannatale A, Ceder S, et al. Tumour exosome integrins determine organotropic metastasis. Nature. 2015;527(7578):329-35.

34. Zhang H, Deng T, Liu R, Bai M, Zhou L, Wang X, Li S, Wang X, Yang H, Li J, et al. Exosome-delivered EGFR regulates liver microenvironment to promote gastric cancer liver metastasis. Nat Commun. 2017;8:15016.

35. Peinado H, Aleckovic M, Lavotshkin S, Matei I, Costa-Silva B, Moreno-Bueno G, Hergueta-Redondo M, Williams C, Garcia-Santos G, Ghajar C, et al. 
Melanoma exosomes educate bone marrow progenitor cells toward a prometastatic phenotype through MET. Nat Med. 2012;18(6):883-91.

36. Costa-Silva B, Aiello NM, Ocean AJ, Singh S, Zhang H, Thakur BK, Becker A, Hoshino A, Mark MT, Molina $\mathrm{H}$, et al. Pancreatic cancer exosomes initiate pre-metastatic niche formation in the liver. Nat Cell Biol. 2015;17(6):816-26.

37. Haderk F, Schulz R: Tumor-derived exosomes modulate PD-L1 expression in monocytes. Sci Immunol. 2017;2(13):eaah5509.

38. Wolfers J, Lozier A, Raposo G, Regnault A, Thery C, Masurier C, Flament C, Pouzieux $S$, Faure F, Tursz T, et al. Tumor-derived exosomes are a source of shared tumor rejection antigens for CTL cross-priming. Nat Med. 2001;7(3):297-303.

39. Zarovni N, Corrado A, Guazzi P, Zocco D, Lari E, Radano G, Muhhina J, Fondelli C, Gavrilova J, Chiesi A. Integrated isolation and quantitative analysis of exosome shuttled proteins and nucleic acids using immunocapture approaches. Methods (San Diego, Calif). 2015;87:46-58.

40. Coumans FAW, Brisson AR, Buzas El, Dignat-George F, Drees EEE, ElAndaloussi S, Emanueli C, Gasecka A, Hendrix A, Hill AF, et al. Methodological guidelines to study extracellular vesicles. Circ Res. 2017; 120(10):1632-48

41. Logozzi M, Angelini DF, lessi E, Mizzoni D, Di Raimo R, Federici C, Lugini L, Borsellino G, Gentilucci A, Pierella F, et al. Increased PSA expression on prostate cancer exosomes in in vitro condition and in cancer patients. Cancer Lett. 2017;403:318-29.

42. Boing AN, van der Pol E, Grootemaat AE, Coumans FA, Sturk A, Nieuwland R. Single-step isolation of extracellular vesicles by size-exclusion chromatography. Journal of extracellular vesicles. 2014;3

43. Hong CS, Funk S, Muller L, Boyiadzis M, Whiteside TL. Isolation of biologically active and morphologically intact exosomes from plasma of patients with cancer. Journal of extracellular vesicles. 2016;5:29289.

44. Rekker K, Saare M, Roost AM, Kubo AL, Zarovni N, Chiesi A, Salumets A, Peters M. Comparison of serum exosome isolation methods for microRNA profiling. Clin Biochem. 2014;47(1-2):135-8.

45. Taylor DD, Shah S. Methods of isolating extracellular vesicles impact downstream analyses of their cargoes. Methods (San Diego, Calif). 2015;87:3-10.

46. Yokoyama S, Takeuchi A, Yamaguchi S, Mitani Y, Watanabe T, Matsuda K Hotta T, Shively JE, Yamaue H. Clinical implications of carcinoembryonic antigen distribution in serum exosomal fraction--measurement by ELISA. PLoS One. 2017;12(8):e0183337.

47. Shih CL, Chong KY, Hsu SC, Chien HJ, Ma CT, Chang JW, Yu CJ, Chiou CC. Development of a magnetic bead-based method for the collection of circulating extracellular vesicles. New Biotechnol. 2016;33(1):116-22.

48. Miyanishi M, Tada K, Koike M, Uchiyama Y, Kitamura T, Nagata S. Identification of Tim4 as a phosphatidylserine receptor. Nature. 2007; 450(7168):435-9.

49. Nakai W, Yoshida T, Diez D, Miyatake Y, Nishibu T, Imawaka N, Naruse K, Sadamura Y, Hanayama R. A novel affinity-based method for the isolation of highly purified extracellular vesicles. Sci Rep. 2016;6:33935.

50. Sharma R, Huang X, Brekken RA, Schroit AJ. Detection of phosphatidylserine-positive exosomes for the diagnosis of early-stage malignancies. Br J Cancer. 2017;117(4):545-52.

51. Gholizadeh S, Shehata Draz M, Zarghooni M, Sanati-Nezhad A, Ghavami S, Shafiee H, Akbari M. Microfluidic approaches for isolation, detection, and characterization of extracellular vesicles: current status and future directions. Biosens Bioelectron. 2017;91:588-605.

52. Yoshioka Y, Kosaka N, Konishi Y, Ohta H, Okamoto H, Sonoda H, Nonaka R, Yamamoto $\mathrm{H}$, Ishii $\mathrm{H}$, Mori $\mathrm{M}$, et al. Ultra-sensitive liquid biopsy of circulating extracellular vesicles using ExoScreen. Nat Commun. 2014;5:3591.

53. Webber J, Clayton A. How pure are your vesicles? Journal of extracellular vesicles. 2013;2

54. Soo CY, Song Y, Zheng Y, Campbell EC, Riches AC, Gunn-Moore F, Powis SJ. Nanoparticle tracking analysis monitors microvesicle and exosome secretion from immune cells. Immunology. 2012;136(2):192-7.

55. Kowal J, Arras G, Colombo M, Jouve M, Morath JP, Primdal-Bengtson B, Dingli F, Loew D. Proteomic comparison defines novel markers to characterize heterogeneous populations of extracellular vesicle subtypes. Proc Natl Acad Sci U S A. 2016;113(8):E968-77.

56. Sun Y, Xia Z, Shang Z, Sun K, Niu X, Qian L, Fan LY, Cao CX, Xiao H. Facile preparation of salivary extracellular vesicles for cancer proteomics. Sci Rep. 2016;6:24669.

57. Jakobsen KR, Paulsen BS, Baek R, Varming K, Sorensen BS, Jorgensen MM. Exosomal proteins as potential diagnostic markers in advanced non-small cell lung carcinoma. Journal of extracellular vesicles. 2015;4:26659.
58. Jorgensen M, Baek R, Pedersen S, Sondergaard EK, Kristensen SR, Varming K. Extracellular Vesicle (EV) Array: microarray capturing of exosomes and other extracellular vesicles for multiplexed phenotyping. J Extracell Vesicles. 2013; 2:20920.

59. Kim DK, Lee J, Kim SR, Choi DS, Yoon YJ, Kim JH, Go G, Nhung D, Hong K, Jang SC, et al. EVpedia: a community web portal for extracellular vesicles research. Bioinformatics. 2015;31(6):933-9.

60. Kalra H, Simpson RJ, Ji H, Aikawa E, Altevogt P, Askenase P, Bond VC, Borras FE, Breakefield X, Budnik V, et al. Vesiclepedia: a compendium for extracellular vesicles with continuous community annotation. PLoS Biol. 2012;10(12):e1001450.

61. Mathivanan S, Simpson RJ. ExoCarta: a compendium of exosomal proteins and RNA. Proteomics. 2009;9(21):4997-5000.

62. Lotvall J, Hill AF, Hochberg F, Buzas El, Di Vizio D, Gardiner C, Gho YS, Kurochkin IV, Mathivanan S, Quesenberry P, et al. Minimal experimental requirements for definition of extracellular vesicles and their functions: a position statement from the International Society for Extracellular Vesicles. Journal of extracellular vesicles. 2014;3:26913.

63. Nolte -'t Hoen EN, van der Vlist EJ, Aalberts M, Mertens HC, Bosch BJ, Bartelink W, Mastrobattista E, van Gaal EV, Stoorvogel W, Arkesteijn GJ, et al. Quantitative and qualitative flow cytometric analysis of nanosized cellderived membrane vesicles. Nanomedicine. 2012;8(5):712-20.

64. van der Vlist EJ, Nolte-'t Hoen ENM, Stoorvogel W, Arkesteijn GJA, Wauben MHM. Fluorescent labeling of nano-sized vesicles released by cells and subsequent quantitative and qualitative analysis by high-resolution flow cytometry. Nat Protocols. 2012;7(7):1311-26.

65. Ibsen SD, Wright J, Lewis JM, Kim S, Ko SY, Ong J, Manouchehri S, Vyas A, Akers J, Chen CC, et al. Rapid isolation and detection of exosomes and associated biomarkers from plasma. ACS Nano. 2017;11(7):6641-51.

66. Sandfeld-Paulsen B, Aggerholm-Pedersen N, Baek R, Jakobsen KR, Meldgaard P, Folkersen BH, Rasmussen TR, Varming K, Jorgensen MM, Sorensen BS. Exosomal proteins as prognostic biomarkers in non-small cell lung cancer. Molecular Oncol. 2016;10(10):1595-602.

67. Yamashita $T$, Kamada $H$, Kanasaki S, Maeda $Y$, Nagano $K$, Abe $Y$, Inoue M, Yoshioka Y, Tsutsumi Y, Katayama S, et al. Epidermal growth factor receptor localized to exosome membranes as a possible biomarker for lung cancer diagnosis. Die Pharmazie. 2013;68(12):969-73.

68. Li Y, Zhang Y, Qiu F, Qiu Z. Proteomic identification of exosomal LRG1: a potential urinary biomarker for detecting NSCLC. Electrophoresis. 2011; 32(15):1976-83.

69. Iliuk $A B$, Arrington JV, Tao WA. Analytical challenges translating mass spectrometry-based phosphoproteomics from discovery to clinical applications. Electrophoresis. 2014;35(24):3430-40.

70. Fang S, Tian H, Li X, Jin D, Li X, Kong J, Yang C, Yang X, Lu Y, Luo Y, et al. Clinical application of a microfluidic chip for immunocapture and quantification of circulating exosomes to assist breast cancer diagnosis and molecular classification. PLoS One. 2017:12(4):e0175050.

71. Moon PG, Lee JE, Cho YE, Lee SJ, Chae YS, Jung JH, Kim IS, Park HY, Baek MC. Fibronectin on circulating extracellular vesicles as a liquid biopsy to detect breast cancer. Oncotarget. 2016;7(26):40189-99.

72. Moon PG, Lee JE, Cho YE, Lee SJ, Jung JH, Chae YS, Bae HI, Kim YB, Kim IS, Park HY, et al. Identification of developmental endothelial locus-1 on circulating extracellular vesicles as a novel biomarker for early breast cancer detection. Clin Cancer Res. 2016;22(7):1757-66.

73. Rupp AK, Rupp C, Keller S, Brase JC, Ehehalt R, Fogel M, Moldenhauer G, Marme F, Sultmann H, Altevogt P. Loss of EpCAM expression in breast cancer derived serum exosomes: role of proteolytic cleavage. Gynecologic Oncol. 2011;122(2):437-46.

74. Khan S, Bennit HF, Turay D, Perez M, Mirshahidi S, Yuan Y, Wall NR. Early diagnostic value of survivin and its alternative splice variants in breast cancer. BMC Cancer. 2014;14:176.

75. Lai X, Wang M, McElyea SD, Sherman S, House M, Korc M. A microRNA signature in circulating exosomes is superior to exosomal glypican-1 levels for diagnosing pancreatic cancer. Cancer Lett. 2017;393:86-93.

76. Li J, Chen Y, Guo X, Zhou L, Jia Z, Peng Z, Tang Y, Liu W, Zhu B, Wang L, et al. GPC1 exosome and its regulatory miRNAs are specific markers for the detection and target therapy of colorectal cancer. J Cell Mol Med. 2017;21(5):838-47.

77. Arbelaiz A, Azkargorta M, Krawczyk M, Santos-Laso A, Lapitz A, Perugorria MJ, Erice O, Gonzalez E, Jimenez-Aguero R, Lacasta A, et al. Serum extracellular vesicles contain protein biomarkers for primary sclerosing cholangitis and cholangiocarcinoma. Hepatology. 2017;66(4):1125-43. 
78. Severino V, Dumonceau JM, Delhaye M, Moll S, Annessi-Ramseyer I, Robin X, Frossard JL, Farina A. Extracellular vesicles in bile as markers of malignant biliary stenoses. Gastroenterology. 2017;153(2):495-504.e498.

79. Hoffman RM. Clinical practice. Screening for prostate cancer. N Engl J Med. 2011;365(21):2013-9.

80. Kawakami K, Fujita Y, Matsuda Y, Arai T, Horie K, Kameyama K, Kato T, Masunaga K, Kasuya Y, Tanaka M, et al. Gamma-glutamyltransferase activity in exosomes as a potential marker for prostate cancer. BMC Cancer. 2017;17(1):316.

81. Overbye A, Skotland T, Koehler CJ, Thiede B, Seierstad T, Berge V, Sandvig K, Llorente A. Identification of prostate cancer biomarkers in urinary exosomes. Oncotarget. 2015;6(30):30357-76.

82. Chen CL, Lai YF, Tang P, Chien KY, Yu JS, Tsai CH, Chen HW, Wu CC, Chung $\mathrm{T}$, Hsu CW, et al. Comparative and targeted proteomic analyses of urinary microparticles from bladder cancer and hernia patients. J Proteome Res. 2012:11(12):5611-29.

83. Beckham CJ, Olsen J, Yin PN, Wu CH, Ting HJ, Hagen FK, Scosyrev E, Messing EM, Lee YF. Bladder cancer exosomes contain EDIL-3/Del1 and facilitate cancer progression. J Urol. 2014;192(2):583-92.

84. Logozzi M, De Milito A, Lugini L, Borghi M, Calabro L, Spada M, Perdicchio M, Marino ML, Federici C, lessi E, et al. High levels of exosomes expressing CD63 and caveolin-1 in plasma of melanoma patients. PLoS One. 2009;4(4):e5219.

85. Shao H, Chung J, Balaj L, Charest A, Bigner DD, Carter BS, Hochberg FH, Breakefield XO, Weissleder R, Lee H. Protein typing of circulating microvesicles allows real-time monitoring of glioblastoma therapy. Nat Med. 2012;18(12):1835-40.

86. Zhao Z, Yang Y, Zeng Y, He M. A microfluidic ExoSearch chip for multiplexed exosome detection towards blood-based ovarian cancer diagnosis. Lab Chip. 2016;16(3):489-96.

87. Li J, Sherman-Baust CA, Tsai-Turton M, Bristow RE, Roden RB, Morin PJ. Claudin-containing exosomes in the peripheral circulation of women with ovarian cancer. BMC Cancer. 2009;9:244.

\section{Submit your next manuscript to BioMed Central and we will help you at every step:}

- We accept pre-submission inquiries

- Our selector tool helps you to find the most relevant journal

- We provide round the clock customer support

- Convenient online submission

- Thorough peer review

- Inclusion in PubMed and all major indexing services

- Maximum visibility for your research

Submit your manuscript at www.biomedcentral.com/submit

) Biomed Central 